\title{
Desafios para resolução de conflitos na Educação Infantil
}

\author{
Desafios para la resolución de conflictos en la educación infantil \\ Challenges for conflict resolution in Early Childhood Education
}

\author{
Cristiane Cardozo Marroche ${ }^{1}$ \\ Lúcio Jorge Hammes²
}

\begin{abstract}
Resumo
O presente artigo visa repensar a educação infantil numa perspectiva da resolução não violenta de conflitos para construir em busca de uma cultura de paz. Tem por base o trabalho pedagógico que busca desenvolver ações que estimam a participação de todos em uma dinâmica dos círculos de aprendizagem formados por professores, atendentes e estagiários. Os processos, desenvolvidos nos círculos favorecem a aquisição de conhecimentos numa relação de entre - ajuda e encontram sua referência básica nos círculos de cultura de Paulo Freire, tendo no diálogo um elemento essencial no processo educativo, respondendo à exigência radical das pessoas que não podem se construir fora da comunicação. Trata-se de uma pesquisa de intervenção com pressupostos da abordagem qualitativa. Os dados foram coletados nos seis círculos de aprendizagem e revelam a importância da manutenção das ações pedagógicas fundamentadas no diálogo, convivência e na cooperação, buscando educar para a paz, resultando na formalização de uma carta com princípios pedagógicos de resolução de conflitos em parceria a comunidade escolar.
\end{abstract}

Palavras-chaves: resolução de conflitos; educação infantil; cultura da paz

\section{Resumen}

El presente artículo tiene por objeto repensar la educación infantil en una perspectiva de la resolución no violenta de conflictos para construir en busca de una cultura de paz. Se basa en el trabajo pedagógico que busca desarrollar acciones que estimulan la participación de todos en una dinámica de los círculos de aprendizaje formados por profesores, asistentes y pasantes. Los procesos, desarrollados en los círculos favorecen la adquisición de conocimientos en una relación entre ayuda y encuentran su referencia básica en los círculos de cultura de Paulo Freire, teniendo en el diálogo un elemento esencial en el proceso educativo, respondiendo a la exigencia radical de las personas que no se pueden construir fuera de la comunicación. Se trata de una investigación de intervención con presupuestos del enfoque cualitativo. Los datos fueron recolectados en los seis círculos de aprendizaje y revelan la importancia del mantenimiento de las acciones pedagógicas fundamentadas en el diálogo, convivencia y en la cooperación, buscando educar para la paz, resultando en la formalización de una carta con principios pedagógicos de resolución de conflictos en sociedad la comunidad escuela.

Palabras claves: resolución de conflictos; educación Infantil; cultura de la paz

\begin{abstract}
This article aims to rethink child education in the perspective of the non - violent resolution of conflicts to build in search of a culture of peace. It is based on the pedagogical work that seeks to develop actions that estimate the participation of all in a dynamic of the learning circles formed by teachers, attendants and trainees. The processes developed in the circles favor the acquisition of knowledge in a relationship between help and find
\end{abstract}

${ }^{1}$ Mestranda em Educação -Universidade Federal do Pampa (UNIPAMPA). Jaguarão/RS (Brasil). Email:crismarroche@gmail.com.

${ }^{2}$ Doutor em educação. Professor da Universidade Federal do Pampa (UNIPAMPA). Jaguarão/RS (Brasil); Email: luciojh@gmail.com. 
their basic reference in the cultural circles of Paulo Freire, having in dialogue an essential element in the educational process, responding to the radical demand of people who can not be build out of communication. It is an intervention research with assumptions of the qualitative approach. The data were collected in the six learning circles and reveal the importance of maintaining pedagogical actions based on dialogue, coexistence and cooperation, seeking to educate for peace, resulting in the formalization of a letter with pedagogical principles of conflict resolution in partnership with the community school.

Keywords: conflict resolution; child education; culture of peace

\section{Introdução}

A sociedade clama por paz. As pessoas não estão convivendo bem umas com as outras, e consequentemente não se comunicam claramente, expressando seus pensamentos e objetivos de forma interativa e consensual.

É na educação infantil que as crianças iniciam sua socialização com colegas, professores, atendentes e o com espaço escolar, criando assim novos vínculos. Esta perspectiva de educação vai ao encontro da perspectiva de Humberto Eco (2000), sugerindo que a educação para a tolerância comece na "mais tenra infância, antes que possa ser escrita em um livro, e antes que se torne uma casca comportamental espessa e dura demais" (ECO, 2000, p.117).

A educação para a tolerância e a paz também tem referência nos estudos de Paulo Freire, pois:

Fica claro que para Paulo a Paz não é um dado, um fato intrinsecamente humano comum a todos os povos, de quaisquer culturas. Precisamos desde a mais tenra idade formar as crianças na "Cultura da Paz", que necessita desvelar e não esconder, com criticidade ética, as práticas sociais injustas, incentivando a colaboração, a tolerância com o diferente, o espírito de justiça e da solidariedade (FREIRE, 2006, p. 391).

Já aprendemos que o diálogo não é mero bate-papo e que "não existe num vácuo político. Não é um espaço livre onde se possa fazer o que se quiser.” (FREIRE, 2008, p.127). O pensamento freireano traz conceitos articulados com objetivo de criar pontes entre a epistemologia de Freire e a educação infantil, a partir do diálogo. A partir de Freire vamos descobrindo bases da educação como construção do conhecimento, amorosidade, colaboração, tolerância, sonho/esperança, escuta, criticidade e curiosidade. É importante enfatizar que na Lei de Diretrizes e Bases da Educação (BRASIL, 1996) e a Referencial Curricular Nacional para a Educação Infantil (BRASIL, 1998), o principal objetivo da educação infantil é o desenvolvimento integral da criança, e isso mostra a importância dos profissionais terem clareza do processo educativo que estão desenvolvendo, os aspectos 
considerados para a efetivação da educação das crianças, ou seja, o objetivo da sua ação pedagógica.

A educação infantil passou por intensas transformações até ser reconhecida na Constituição de 1988, no Estatuto da Criança e do Adolescente (BRASIL, 1990) e na Lei de Diretrizes e Bases da Educação Nacional (BRASIL, 1996) como a primeira etapa da educação básica no Brasil, abarcando as crianças de 0 a 6 anos.

Este artigo busca repensar a educação infantil numa perspectiva da resolução não violenta de conflitos para construir em busca de uma cultura de paz nos contextos escolares, com as pessoas que estão intrinsecamente envolvidas com educação das crianças, os atendentes e professores ligados ao CIEE (Centro de Integração Empresa-Escola).

\section{Metodologia do trabalho}

O estudo teve uma abordagem metodológica qualitativa, intervencionista a partir de círculos de aprendizagem numa perspectiva freireana, propiciando a criação de um espaço onde prevaleceu a fala e a escuta qualificada.

A população do estudo foi constituído por 6 professores que atuam do maternal à préescola; 10 estagiários do CIEEE, 3 atendentes e 3 da equipe diretiva da escola, totalizando 22 sujeitos de pesquisa.

A proposta metodológica constituiu-se de círculos de aprendizagem com os profissionais que possibilitaram aprofundamento de estudos, reflexões e discussões sobre a problemática central: desafios para resolução de conflitos na Educação Infantil. Foram propostos 6 círculos de aprendizagem presencial e trabalhos com as turmas onde os sujeitos da pesquisa fazem parte. Foi uma oportunidade importante para escutar e dialogar com os profissionais que atuam na escola.

Para fins de intervenção, a escolha dos círculos de aprendizagem se deu por proporcionarem momentos de diálogo e discussões responsáveis, indo ao encontro a proposta freireana, de formação colaborativa e da busca coletiva por novos conhecimentos que refletirão na experiência de cada sujeito.

A proposta dos círculos de aprendizagem é melhor compreendida se a relacionarmos com os círculos de cultura de Freire, definindo que: "Estes círculos encontram sua referência básica no diálogo, entendido como um elemento essencial no processo educativo, e respondem à exigência radical das pessoas que não podem se construir fora da comunicação" (HAMMES et al, 2017 p.104). 
Neste sentido, os círculos de aprendizagem, no contexto desta pesquisa, envolvêramos professores efetivos, atendentes efetivos e estagiários ligados ao CIEE em comunhão e na busca do conhecimento, repensando a educação infantil na EMEI Gov. Leonel de Moura Brizola. Os profissionais foram selecionados conforme disponibilidade e interesse na busca e produção de novos conhecimentos.

\section{Discussão e resultados}

A criança começou a ser vista como ser social, perdendo a visão somente assistencialista e assumindo uma visão pedagógica. Bujes (2001, p. 16) destaca que “A educação da criança pequena envolve simultaneamente dois processos complementares e indissociáveis: educar e cuidar", mostrando que as crianças nessa etapa necessitam de atenção, de carinho e de segurança para se desenvolver de forma integral. Destaca-se que uma prática que proporcione às crianças se expressar de forma peculiar e original, estimulando sua criatividade, imaginação e fantasia. As crianças desafiam na sua peculiaridade e diferença por cuidado a considerar e desenvolver um trabalho a partir desta sua identidade.

Para Zabalza (1998, p. 19) "a escola infantil deve postular a 'identidade e autonomia' dotando as crianças das competências, aptidões, hábitos e atitudes que lhes favoreça boas aprendizagens".

Conforme Bujes (2001), estudos na área de educação infantil é dever da escola educar e cuidar, desenvolvendo um ensino afetivo, com olhar atento a não promover ações pedagógicas sem sentido. Cuidar e educar devem andar juntos, pois a escola é um espaço que visa o desenvolvimento global do aluno. Sendo assim, é imprescindível que a comunidade escolar conheça a realidade de cada aluno, é olhar todo o cotidiano escolar, é respeitar a individualidade e perceber o aluno como sujeito de direitos, previsto na lei.

Dessa forma, torna-se importante uma prática dialógica onde os profissionais se percebam como agentes de transformação e, junto às crianças, busquem harmonicamente uma cultura pela da paz.

Estudos no Livro de Registro de Ocorrência ${ }^{3}$ revelam casos de agressão que ocorrem por falta da intervenção adequada de professores, atendentes e ou estagiários (CIEEs). Isso se dá não só pelo fato de não se importarem, mas por não terem um conhecimento amplo a respeito deste fenômeno e não saberem como intervir de forma eficaz. Por este motivo,

\footnotetext{
${ }^{3}$ Livro de Registro de Ocorrência é um livro onde a direção anota os registros de ocorrências que são comunicados na escola. Ele fica na secretaria da escola e tem acesso a este livro a direção da escola especialmente sob os cuidados da Coordenadora Acadêmica e a Diretora da Escola.
} 
tornou-se importante os círculos de aprendizagem para que pudéssemos dialogar, desabafar os anseios e frustrações diante da resolução de conflitos, a fim de prepará-los para mediar os conflitos e usá-los como instrumento para construir um cultura de paz em na escola, de forma prática e duradoura.

As instituições de Educação Infantil propiciam ambientes importantes para o desenvolvimento das relações sociais e de cooperação. Assim, o profissional pode aventurarse a evitar o surgimento de conflitos através das ações pedagógicas. No entanto, não seria o momento propício de intervir trabalhando os valores e regras indispensáveis para o convívio social? Neste sentido uma grande preocupação é como lidar e identificar o que é conflitos.

\begin{abstract}
Um exemplo claro da dificuldade que temos para lidar com o conflito é a nossa incapacidade de identificar as circunstâncias que derivam do conflito ou redundam nele. Em geral, nas escolas e na vida, só percebemos o conflito quando este produz suas manifestações violentas. Daí podemos tirar, pelo menos, duas conclusões: a primeira é que se ele se manifestou de forma violenta é porque já existia antes na forma de divergência ou antagonismo, e nós não soubemos ou não fomos preparados para identificá-lo; a segunda é que toda a vez que o conflito se manifesta, nós agimos para resolvê- lo, coibindo a manifestação violentas . E neste caso, esquecemos que problemas mal resolvidos se repetem! (CHRISPINO; CHRISPINO, 2002)
\end{abstract}

A escola está historicamente acostumada a lidar com um tipo padrão de aluno, que recebe a regra e apresenta o resulta imediato. A realidade escolar na educação infantil hoje necessita de uma ponderação bastante abrangente em como lidar com o comportamento, muitas vezes agressivo, dos alunos, na verdade a questão é como mediar os conflitos que se tornam agressivos? A partir de alguns pesquisadores "agressão é qualquer comportamento com intenção de ferir alguém física ou verbalmente” (WEITEN, 2002, p. 387).

Esta agressão poderia ser subdivida em três formas, tais como "a agressão instrumental: empregada para obter ou reter um brinquedo ou outro objeto qualquer; a agressão reativa: a retaliação raivosa em função de um ato intencional ou acidental; a agressão ameaçadora: um ataque de agressão espontâneo" (BERGER, 2003, p. 202)

Conforme Berger (2003, p. 202) ainda, a agressão se inicia "a partir de um autoconceito e de uma regulação emocional inadequado durante os primeiros anos da préescola e pode se tornar um sério problema social à medida que o tempo passa".

Para muitos há falta de conhecimento e se surpreendem com estas questões e leituras. Porém, diversos profissionais da educação infantil vêm se deparando com o fenômeno dos conflitos e agressividades infantis, resultando da falta de preparação que os deixam inseguros e incapacitada para a mediação de forma a não agravar a situação. 
Entendemos que não cabe indicar culpa da escola ou de familiares. No entanto muitos estudos enfatizam que o ambiente familiar, é um dos, senão o principal, influenciador dos comportamentos agressivos. Lisboa (2006, p. 55) afirma:

Eis como você cria uma criança violenta: ignore-a, humilhe-a e provoque-a. Grite um bocado. Mostre sua desaprovação a tudo o que ela fizer. Encoraje-a a brigar com irmãos e irmãs. Brigue bastante, especialmente no sentido físico, com seu parceiro conjugal na frente da criança. Bata-lhe bastante. Eu adicionaria: ameace-a, castiguea, engane-a, minta-lhe, seja permissivo, ensine-a que o mundo é dos 'vivos', vangloriando-se diante dela de atos dos quais deveria se envergonhar (...).

Os profissionais que atuam na educação infantil estão intrinsecamente envolvidos com os alunos, no entanto muitos não têm uma capacitação para exercer a função que lhe foi dada ou não se sentem parte daquele âmbito escolar. Gerando um empasse em como tratar de forma adequada os comportamentos que fogem dos ditos "normais", usando do castigo e ameaças verbais, comumente esse procedimento é percebido pelos alunos como forma de receber atenção dos pais e dos profissionais.

Neste sentido Hammes (2009) afirma que:

A situação de hoje requer a elaboração de estudos e ações que vão ao encontro da paz duradora. Por isso, pode ser necessário elaborar novos "tratados de paz", mas também a formação de pessoas para que possam conviver com o diferente e resolver os conflitos de modo não-violento.

Propõe-se um "movimento pela paz", com um convite especial para aqueles que mais sofreram pela falta de paz. A sociedade civil pode mobilizar iniciativas de paz antes que a crise esteja fora de controle e vidas sejam perdidas. (p.17)

O autor apresenta uma expressiva importância na formação de mediadores de conflitos no contexto escolar em que convivemos.

Conforme os participantes dos círculos de aprendizagem os temas abordados em cada encontro foi relevante para capacitação, interação e a reflexão, e principalmente propôs uma abordagem diferente do cotidiano, onde todo(s) professor/atendentes/estagiários trocaram experiências e dialogassem sobre a prática pedagógica.

A cada círculo de aprendizagem foi abordado uma temática, destacando as concepções de resolução de conflitos na Educação Infantil, uma das professoras afirma que: "Conflitos fazem parte do desenvolvimento da criança, o problema ocorre quando esses conflitos ultrapassam os limites de respeito com o outro, como agressões físicas e verbais".

Já, uma estagiária (CIEEs), participante, afirmou:

Deparo-me com situações de conflitos no cotidiano, coleguinhas se mordendo, batendo uns nos outros por nenhum motivo, apenas porque a coleguinha passou ao lado. Crianças de 3 anos falando "palavrões", crianças de 5 anos apresentando algum tipo de crise, gritando sem parar,...Isso depende da sala, a momentos de tanta 
angústia e estresse, que a vontade largar o contrato e desistir. Se não houver um momento de saída da sala para respirar um pouco, se surta.

Questionadas sobre a cultura da paz como uma construção a partir da convivência, cooperação e diálogo, os professores/atendentes/estagiários responderam:

Educação é uma evolução constante do conhecimento, onde através da interação professor $\mathrm{x}$ aluno, convivem dialogando e trocando experiência para um bom aprendizado, onde ambos ganham...a desestruturação da família e a falta de limite é o maior obstáculo a ser vencido.

Pra mim a educação está ligada a convivência familiar e quando não há essa educação em casa , a falta de educação se manifesta na sala de aula.

Educação para mim vem do amor de querer repassar o que temos de melhor entre nós... Paz é manter o convívio e o diálogo ativo...

Dialogando sobre o favorecimento de estratégias para resolução e conflitos, e as ações de mediação de conflitos as professoras participantes destacam:

Acho de grande importância à mediação de conflitos, através dela é possível resolver várias questões que surgem no dia a dia. Contribuindo de forma positiva a formação das crianças.

Nós sabemos que nas nossas aulas, existem muitos conflitos no dia a dia... Precisamos saber como mediar essas situações, pois elas são mais cotidianas do que estão fora da sala imaginam.

Discutindo se a resolução de conflitos foi abordada na sua formação inicial para atuar na Educação Infantil os estagiários (CIEEs) descreveram:

Eu acho importante, principalmente para os CIEEs, era para ter algum curso ou palestra, algo que ajudasse mais os CIEEs antes de começarem a trabalhar na creche, pois a maioria não, todos, quando começam a trabalhar na creche não estão preparados, para conviver com tudo que acontece no dia a dia, o pior que tem muitos que não estão preparados, mas que acham que estão.

Quando discutido e questionado sobre a educação para paz: Paz se ensina? Paz se aprende? A educação para a paz como espaço de construção coletiva? O participante salientou:

Acredito que a compreensão de paz vai além de saber o significado da palavra, é uma jornada de aprendizagem. Para saber ensinar qualquer tipo de afeto acho que tem que partir de nos mesmo, sentir para repassar. A paz deve ser cultivada no coletivo, como respeito e humanização ao próximo.

$\mathrm{Na}$ avaliação dos círculos de aprendizagem intitulada "Desafios da resolução de conflitos na Educação Infantil" e com objetivo geral "Repensar a educação infantil numa perspectiva da resolução não violenta de conflitos para construir em busca de uma cultura de paz, professores, atendentes e estagiários (CIEEs)participantes escreveram que consideram estes momentos: 
Acredito que os encontros foram muito proveitosos, nos fizeram pensar sobre a nossa prática pedagógica. Fizemos boas trocas de experiências com os colegas. Outra coisa boa foi ter o contato com os colegas.

Foram encontros de grande relevância, momentos únicos onde professores, atendentes e estagiários puderam apresentar suas ideias, seus objetivos e até mesmo nossos medos e fracassos. Acredito que seria se suma importância à continuação desses encontros.

Nossos encontros coma professora Cristiane deveriam ser semanalmente, pois foi muito produtivo, sendo que ela transmite, confiança, paz, tranquilidade, diálogo, e um suporte que deveríamos ter no dia a dia.

Outra professora destacou a importância sobre o assunto:

Os círculos de aprendizagem contribuíram de forma positiva, fez com que nós educadores façamos uma reflexão sobre nossa prática, aprimorando nosso modo de pensar e agir, e perceber o quanto nosso papel é importante na sociedade.

A educação para a paz é tema de estudos de educadores, filósofos, sociólogos, antropólogos psicólogos de diversos países, com propósitos variados.Nesta mesma perspectiva a UNESCO, vem investido na busca pela paz através da educação. $\mathrm{O}$ artigo $1^{\circ}$ da Declaração da ONU declara que "Uma Cultura de Paz é um conjunto de valores, atitudes, tradições, comportamentos e estilos de vida baseados: No respeito à vida, no fim da violência e na promoção e prática da não violência por meio da educação, do diálogo e da cooperação (...)". Fica evidente, que a escola, enquanto espaço de desenvolvimento humano, trabalhe na busca de uma prática dialógica, em prol da paz, ponderando pedagogicamente a criação de espaços interativos que promovam a esperança de como entender o mundo.

Há uma relação entre a alegria necessária à atividade educativa e a esperança. A esperança de que professor e alunos juntos podemos aprender, ensinar, inquietarnos, produzir e juntos igualmente resistir aos obstáculos à nossa alegria. Na verdade, do ponto de vista da natureza humana, a esperança não é algo que a ela se justaponha. A esperança faz parte da natureza humana.( FREIRE, 1996, p. 80)

A criança quando chega à escola traz consigo uma bagagem cultural, possuindo um modo próprio de se expressar no mundo. No entanto, é preciso assumir, como educadores, a tarefa, fazendo com que a ação pedagógica não transforme e forme para desumanização, uma vez que, crianças vivem umas realidades familiares de exploração, desafeto e violência. Principalmente na Educação Infantil é amplamente necessária a reflexão de todos os que estão envolvidos com a educação das crianças, sobre as ações que são vivenciadas cotidianamente. Partindo de um posicionamento claro sobre o quê ensinam e o que aprendem na Educação Infantil em favor da humanização e ressignificando à infância. 
De acordo com as palavras de Freire(1998, p. 43) "é na formação permanente dos professores, o momento fundamental é o da reflexão crítica sobre a prática. É pensando criticamente a prática de hoje ou de ontem que se pode melhorar a próxima prática".

\section{Algumas repercussões da formação docente na sala de aula}

Uma das decorrências constatadas, tão logo as professoras e estagiários (CIEEs) que participaram dos círculos de aprendizagem, foi o desenvolvimento de ações junto aos alunos em sala de aula, desenvolveram-se atividades bastante relevantes com os alunos, colocando em prática aquilo que foi solicitado e discutido no grupo.

a) Atividades realizadas pelo professor do Pré - B II sobre diversidade e o respeito ao próximo.

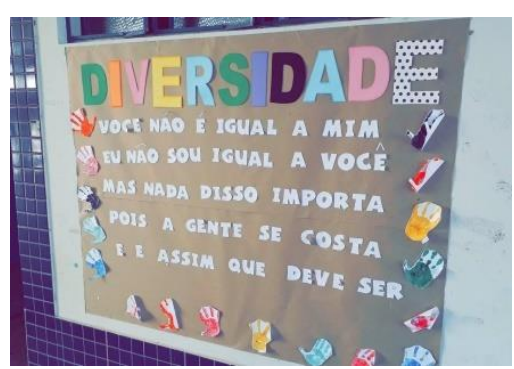

b) Atividades solicitadas nos círculos de aprendizagem para os participantes realizarem na sala de aula sobre educação, paz, convivência, amizade, cooperação e diálogo.

c) A equipe diretiva envolvidos com o projeto desenvolveu um projeto pedagógico sobre Gentileza, realizando atividades e dinâmicas no saguão da escola com as crianças, professores, atendentes e estagiários.

Os dados mostram que o diálogo através dos círculos de aprendizagem pode levar a novas práticas, envolvendo alunos e comunidade numa dinâmica que leva a busca da construção de uma sociedade melhor.

\section{Considerações finais}

As discussões sobre os a resolução de conflitos na Educação Infantil é um tema que está na ordem do dia-a-dia. Os círculos de aprendizagens desenvolvidos nesta escola municipal geraram reflexões benéficas, possibilitando um espaço de interação, desabafos, debates sobre ideias e, dessa forma pensar sobre a prática docente em relação à resolução de conflitos. 
A partir dos estudos nos Círculos compreendeu-se que, ao longo da história, a Educação Infantil obteve mudanças educacionais que o levaram a ser parte integrante da educação básica e os olhares se voltaram ao direito das crianças. Ainda que haja muito que investir nessa área, especialmente aprofundandoa questão curricular e de atuação profissional. É necessário que todo o contexto escolar assuma o compromisso de propiciar momentos para construção de uma educação igualitária, que respeite e se constitua na paz.

Além de compreender que as ações pedagógicas se constituem de um processo de formação continuo dos profissionais para atuar com a educação das crianças. Conforme Freire (2008), a efetivação do diálogo vai além de palavras, os educadores carecem de observação atenta e crítica ao que está acontecendo, desde seus interesses das crianças, experiências e expressões, possibilitando a reflexão sobre sua visão de organização do ensino-aprendizagem.

Portanto a educação para paz é essencial nos dias atuais na formação de professores e demais profissionais ligados a Educação Infantil, pois cada vez mais as escolas estão recebendo alunos com comportamentos diversos, e muitas vezes entram em conflito com a sua própria prática por não saber mediar e lidar com a situação.

Para o desenvolvimento dos círculos de aprendizagem partiu-se do princípio de que para a resolução de conflitos é importante proporcionar o diálogo e discussões de forma democrática. Não cabe julgar nem um profissional ou ação pedagógica, porquanto, entendo que a aprendizagem se torna mais interessante quando o aluno se sente motivado em sala de aula , quando tem prazer pelo aprender, se isso não ocorre ele tem a sala de aula como uma tarefa a cumprir, encarando como obrigação. Para que isto não ocorra, o profissional deve despertar a curiosidade dos alunos, acompanhando suas ações no desenvolver das atividades, sendo imprescindível o diálogo que é (...) uma espécie de postura necessária, na medida em que os seres humanos se transformam cada vez mais em seres criticamente comunicativos. $\mathrm{O}$ diálogo é o momento em que os seres humanos se encontram para refletir sobre sua realidade tal como a fazem e a refazem (FREIRE, 2008, p.123)

Os professores, atendentes e estagiários (CIEEs) participantes avaliaram o tema de total importância, visto que situações de conflito na escola e a falta de comprometimento dos pais ou responsáveis incidem frequentemente, e não são de fácil solução, sendo necessária orientação, pois um conflito mal resolvido pode evoluir para uma situação de violência. 


\section{Referências}

ARIÈS, Philippe. História social da criança e da família. Rio de Janeiro: Zahar Editores, 1973.

BERGER, K. S. O Desenvolvimento da Pessoa: da infância à adolescência. Rio de Janeiro: LTC editora, 2003.

BRASIL. Constituição. Constituição da República Federativa do Brasil. Brasília. Promulgada em 5 de outubro de 1988.

.Lei n. ${ }^{\circ}$ 8069, de 13 de julho de 1990. Dispõe sobre o Estatuto da Criança e do Adolescente e dá outras providências.

Ministério da Educação. Lei n. ${ }^{\circ}$ 9394/96. Lei de Diretrizes e Bases da Educação Nacional. Dezembro de 1996.

Ministério da Educação e Cultura. Lei de Diretrizes e Bases da Educação Nacional. Lei $\mathrm{n}^{\circ}$ 9394, de 20 de dezembro de 1996. Dispõe sobre as Diretrizes e Bases da Educação Nacional. Brasília, DF: MEC, 1996. 164 Cadernos de Educação: Ensino e Sociedade, Bebedouro-SP, 1 (1): 151-164, 2014.

Ministério da Educação e do Desporto. Referencial Nacional Curricular Nacional para a Educação Infantil. Vol.1. Brasília: MEC/SEF, 1998.

Ministério da Educação. Secretaria da Educação Básica. Indicadores de qualidade na Educação Infantil. Brasília: MEC/SEB, 2009.

BUJES, Maria Isabel E. Escola Infantil: pra que te quero. In: CRAIDY, Carmem; KAERCHER, Gládis E. (orgs.). Educação Infantil pra que te quero?. Porto Alegre: Artmed, 2001.

CHRISPINO, Álvaro. Gestão do conflito escolar: da classificação dos conflitos aos modelos de mediação. Ensaio: aval. pol.públ. Educ., Rio de Janeiro, v.15, n.54, p. 11-28, jan./mar. 2007. Disponível em: http://www.scielo.br/pdf/ensaio/v15n54/a02v1554. Acessado em: 23 dez 2108. (Artigo em Periódico Digital)

ECO, Umberto. Cinco Escritos Morais. Trad. Eliana Aguiar. Rio de Janeiro: Record, 2000.

FREIRE, Nita. Educação para a paz segundo Paulo Freire. Educação. Porto Alegre - RS, ano XXIX, n. 2 (59), p. 387 - 393, Maio/Ago. 2006.

FREIRE, Paulo. Medo e ousadia. São Paulo: Editora Paz e Terra, 2008

FREIRE, Paulo. Pedagogia da autonomia: saberes necessários à prática educativa. São Paulo: Paz e Terra, 1996.

HAMMES, Lúcio Jorge; SELAU, Bento e MELGAR JR., Eduardo Carralaga. Círculos de aprendizagem: internet e o trabalho colaborativo. Signos. Lajeado, v. 35, n. 2, p. 103-117, 2014. Disponível em: http://www.univates.br/revistas/index.php/signos/article/view/777/767. Acessado em: 23 dez 2108. (Artigo em Periódico Digital) 
LISBOA, A.M.J. A Primeira Infância e as raízes da Violência. Brasília: LGE Editora, 2006.

SELAU, Bento; HAMMES, Lúcio Jorge. Educação Inclusiva e Educação para a Paz: relações possíveis. São Luis/MA: EDUFMA, 2009.

WEITEN, W. Introdução à Psicologia: Temas e variações. São Paulo: Pioneira Thomson, 2002.

ZABALZA, M. Diários de classe. Porto: Porto Editora, 1994. Disponível em: https://pactosllirios.wordpress.com/2013/05/18/caderno-de-metacognicao. Acessado em: 23 $\operatorname{dez} 2108$. 